Dossiê

Ensino e Pesquisa em História Antiga e História Medieval no Brasil

\title{
A BELA MISSÃO DE ENSINAR: A POESIA DIDÁTICA A PARTIR DAS OBRAS DE LUCRÉCIO E MANÍLIO (SÉCULOS I a.C. - I d.C.)
}

\author{
THE BEAUTIFUL MISSION OF TEACHING: THE DICACTIC POETRY FROM THE \\ WORKS OF LUCRETIUS AND MANILIUS (CENTURIES I B.C. - I D.C.)
}

Rodrigo Santos Monteiro Oliveira*

\begin{abstract}
RESUMO
A poesia didática expressa um conhecimento para alguém e, dessa forma, elege em sua composição dois personagens principais ao longo de narrativa: o professor, ou seja, aquele que ensina; e o aluno, a quem o ensinamento é direcionado. Tal articulação pode ser percebida pela utilização da primeira pessoa na elaboração do texto, o que nos dá a impressão de um discurso falado a alguém de maneira direta. Ao evocarem seu compromisso com a matéria e alertarem seus alunos a respeito do tortuoso caminho da aprendizagem, Lucrécio e Manílio constroem seu próprio percurso retórico a fim de legitimarem aquilo que afirmam ser necessário para o bem-estar geral. Concomitantemente, os autores percebem a necessidade dos adornos característicos das grandes poesias épicas a fim de tornarem atrativas as experiências de aprendizado aos seus interlocutores; como um médico que adoça com o mel o medicamento amargo ministrado aos seus pacientes, os poetas se utilizam da poesia para transmitir conbecimentos de alto valor. Por esta razão analisaremos as obras De rerum natura $e$ Astronomicas, entendendo o gênero literário especificado a partir de um projeto educacional particular de ambos os poetas, ao mesmo tempo em que representavam os anseios de sua sociedade e de seus pares.
\end{abstract}

PALAVRAS-CHAVE: Poesia didática. Educação. Epicurismo. Universo.

\begin{abstract}
Didactic poetry expresses knowledge for someone and, in this way, elects in its composition two main characters throughout its narrative: teacher, that is, the one who teaches; and the student, to whom the teaching is directed. Such articulation can be perceived by the use of the first person in the elaboration of the text, which gives us the impression of a speech spoken to someone directly. By evoking their commitment to the subject and alerting their students to the tortuous path of learning, Lucretius and Manilius build their own rhetorical path in order to legitimize what they say is necessary for the general well-being. Concomitantly, the authors perceive the need for the characteristic adornments of great epic poetry in order to make learning experiences attractive to their interlocutors; like a doctor who sweetens the bitter medicine given to his patients with honey, poets use poetry to transmit knowledge of high value. For this reason, we will analyze the works De rerum natura and Astronomicas, understanding the literary genre specified from a particular educational project of both poets, while representing the desires of their society and their peers.
\end{abstract}

KEYWORDS: Didactic poetry. Education. Epicureanism. Universe.

\footnotetext{
* Mestre em História pela Universidade Federal de Goiás. E-mail: rodrigo.sm.oliveira@gmail.com
} 
Longinus, autor de Sobre o sublime, aponta que os que escrevem buscam reconhecimento e, ao produzirem literatura, objetivam também transcender o humano, pois a representação realizada suplementa a natureza, possibilitando, então, que se alcance a perfeição (LONGINUS. Sobre o sublime, XXXVI: 110-111). Tal seria, igualmente, a intenção de nossos autores que se apresentam como responsáveis pelo ensino de temas tão complexos, mas necessários; apresentam-se, assim sendo, como professores de saberes essenciais, exigindo de seus públicos/alunos a atenção necessária para seguir com a difícil empreitada.

Não sabemos a quem Manílio se dirigia especificamente, enquanto conhecemos nominalmente o alvo de Lucrécio, Mêmio. Mesmo que assim seja feito por Lucrécio (exceção dentro do gênero didático), não podemos desprezar que sua mensagem se destinava a um público provavelmente bem maior, sendo Mêmio apenas um representante daqueles que almejava alcançar. Difícil tarefa a de conceber o papel do leitor na Antiguidade, já que são poucos os registros que temos a respeito de como as obras foram, em seus respectivos contextos, recebidas; trabalhar com a recepção das poesias didáticas é ainda mais difícil, pois não falamos de um espaço de compartilhamento insignificante, mas analisamos um grande Império, territorialmente extenso.

Sabemos que obras diversas "viajavam” pelo território romano, sendo exemplo disso as obras de Plauto (século III a.C.), primeiro autor latino que adaptou comédias gregas. O alcance de tais versões era diverso, pois as peças eram apresentadas em festivais públicos, nos quais também aconteciam outras apresentações artísticas e esportivas. Fora os festivais, e a partir da introdução, cada vez maior, da cultura grega no território romano - especificamente, na cidade de Roma -, grandes homens, como Cipião, tinham à sua disponibilidade grandes bibliotecas, permitindo aos próximos e interessados que usufruíssem de todo o material acumulado. Conforme Casson (2018, p. 80), "todas as indicações são de que, por volta da metade do segundo século a.C., havia copiosos recursos de bibliotecas na cidade de Roma", particulares, dispersas e abertas para uns poucos selecionados.

A situação muda já no primeiro século a.C., quando, enriquecida pelas guerras travadas na Grécia e na Ásia Menor contra reinos helenísticos, Roma adquire ainda mais recursos para as bibliotecas existentes. Não foram apenas as pilhagens que possibilitaram a formação das bibliotecas em Roma. Homens devotados ao conhecimento acumularam uma série de coleções e escritos a partir da cópia de manuscritos gregos e da troca de correspondências que poderiam contar com a aquisição de obras escritas pelos contemporâneos (assim, por exemplo, Cícero conseguiu sua cópia de Sobre a natureza das coisas, tecendo comentário a respeito do trabalho lucreciano em carta ao seu irmão Quinto (CICERO. Cartas a Quintus, II: 9).

Mesmo com a existência de uma maioria de estabelecimentos privados, a elite romana não se privou de acessar conteúdos e obras diversas; de circular, inclusive, aquilo que produziam. E e é mais uma vez Cícero quem nos concede um vislumbre sobre como isso acontecia:

Quando estava na minha casa em Túsculo e queria consultar certos livros na biblioteca do jovem Lúculo, fui à sua vila para obtê-los eu mesmo, como sempre 
fiz. Quando cheguei, eu vi Marco Catão, que eu não sabia que lá estava, sentado entre uma pilha de livros sobre estoicismo (CICERO. O fim do bem e do mal, III: 8). ${ }^{1}$

Percebemos que os interessados em trabalhos específicos, quando usufruíam de status social importante, poderiam consultá-los em outras bibliotecas particulares, o que explica a possibilidade de circulação das obras passadas e existentes. Também era prática comum o empréstimo de exemplares e a realização de cópias. Presentear alguém influente com livros era, igualmente, um mecanismo utilizado pelos escritores para, com isso, divulgarem suas obras e, uma vez enviado, o livro entrava, por assim dizer, em domínio público, sendo permitido a qualquer um produzir uma cópia (CASSON, 2018, p. $92) .^{2}$

Era possível, também, comprar livros na taberna libraria, basicamente um scriptorium que realizava cópias. Ao final da República e início do Império, inúmeras outras bibliotecas foram construídas, sendo os próprios Imperadores entusiastas de tais projetos. Não há grande questionamento a respeito de quem era o público: escritores, advogados, filósofos, professores ou ao menos todos aqueles que possuíam algum interesse profissional ou que estavam em constante trabalho de erudição e nutriam algum valor pela literatura. Durante o Império, com o domínio cada vez maior de novos territórios, Roma torna-se centro de estudo (dividindo espaço com outros grandes e mais antigos: Alexandria, por exemplo), pois torna-se o cerne da civilização e a canalização da romanização era necessária para a manutenção administrativa. Aumentou, então, o número de compradores de livros, e livrarias disponibilizavam cópias já previamente feitas de grandes poetas, trabalhos famosos e muito procurados. Indicação de que essa atividade era comum desde a segunda metade do primeiro século a.C., está presente em Horácio (Epistolas, I: 20.2), ao afirmar que sua obra estava disponível para venda na loja da família Sossi. Em outra obra, o mesmo autor alega que o poeta capaz de aliar o deleite poético com a divulgação de preceitos úteis será amplamente divulgado por livreiros e, até mesmo, em terras distantes (HORÁCIO, Arte Poética, 345). ${ }^{3}$

Por isso, alguns pressupostos devem ser destacados antes de avançarmos mais: nossos autores se dirigiam à elite romana, especificamente àquela da cidade de Roma, pois desejavam, com seus ensinamentos, livrar seus contemporâneos dos problemas e da violência vividos. Defendemos esta hipótese pela análise de ambas as obras em diálogo com a teoria da estética da recepção desenvolvida por Hans Robert Jaus e Wolfgang Iser, principalmente.

“Como a palavra, uma frase, uma carta, assim também a obra literária não é escrita no vazio, nem dirigida [apenas] à posterioridade; é escrita sim para um destinatário concreto" (NAUMANN, 1973 , p. 58). Se o acesso ao leitor, enquanto interlocutor na construção de uma obra escrita qualquer, é

\footnotetext{
1 "causa autem fuit huc veniendi ut quosdam hinc libros promerem. et quidem, Cato, hanc totam copiam iam Lucullo nostro notam esse oportebit; nam his libris eum malo quam reliquo ornatu villae delectari."

2 “Na época da República Romana, o principal caminho pelo qual os livros entravam em circulação era pela apresentação, feita pelos autores, de cópias de suas obras para amigos, colegas escritores, patronos, proprietários de coleções privadas e afins. Este continuou a ser um importante caminho mesmo depois da criação das bibliotecas públicas, uma vez que os autores acrescentaram à sua lista de recpetores. Eles estavam ávidos por terem suas obras nas prateleiras; isso era uma marca de status, bem como uma entrée para um círculo maior de leitores" (CASSON, 2018, p. 119).

3 "hic meret aera liber Sosiis, hic et mare transit et longum noto scriptori prorogat aevum."
} 
difícil ao pensarmos os trabalhos que se dedicam ao estudo da literatura contemporânea, quando pensamos tal relação no Mundo Antigo temos a dificuldade temporal contrária a qualquer proposta definitiva. Mesmo que entendamos os prováveis caminhos percorridos pelas obras escritas, não podemos afirmar categoricamente que a recepção se constituía a partir de um modelo único - ainda que possamos conjecturar hipóteses. Assim estabelecemos, pois entendemos que todo aquele que escreve pensa um leitor ideal, alguém que o compreenda e o aceite; pensa em seu contexto e nos signos que formam o coletivo e, assim, fazem de sua obra algo inteligível aos demais. Espera-se o sucesso, sendo este conquistado a partir de um ajuste entre o horizonte de expectativas dos leitores com o horizonte possibilitado pelo texto (LIMA, 1979, p. 44).

O reconhecimento do leitor naquilo que lê se produz a partir desta alteridade em que identifica-se a diferença do outro a partir do estoque pessoal de pré-noções. Por assim ser, a reação do leitor, então, é uma experiência de corroboração dos valores socialmente aceitos; "sempre falamos de algum ponto" (LIMA, 1979, p. 49). Porém, identificar com exatidão esse "leitor ideal" (mesmo em nosso caso, no qual Lucrécio nomeia seu "aluno", Mêmio), não é possível e, em certa medida, é infecundo. ${ }^{4} \mathrm{O}$ que identificamos é um leitor implícito que não é qualquer um, pois parte-se do pressuposto de que este compreende o significado da obra lida de acordo com os horizontes de exigências e expectativas criados pelo autor e semelhantes ao do leitor (não iguais); e, em nosso caso, esse leitor é localizável a partir de um grupo social pequeno (ISER, 1979, p. 105-118). Destaca Jauss (1994, p. 29):

Mas a possiblidade da objetivação do horizonte de expectativa verifica-se também
em obras historicamente menos delineadas. E isso porque, na ausência de sinais
explícitos, a predisposição específica do público com a qual um autor conta para
determinada obra pode ser igualmente obtida a partir de três fatores que, de um
modo geral, se podem pressupor: em primeiro lugar, a partir de normas conhecidas
ou da poética imanente ao gênero; em segundo, da relação implícita com obras
conhecidas do contexto histórico-literário; e, em terceiro lugar, da oposição entre
ficção e realidade, entre a função poética e a função prática da linguagem, oposição
esta que, para o leitor que reflete, faz-se sempre presente durante a leitura, como
possiblidade de comparação.

Nosso leitor/aluno implícito é alguém que entenderia as propostas realizadas; compreenderia o Epicurismo exposto por Lucrécio e a astrologia estoica de Manílio - não seria, por isso, qualquer um. A exemplo da astrologia, temos que lembrar de que tal período - da dinastia Júlio-Claudiana - foi marcado pela forte presença deste saber. Este foi considerado um assunto demonstrativo de muita eloquência, como no caso apresentado pela obra Satíricon, de Petrônio, quando Trimalquião esbanja conhecimento ao tentar falar sobre astrologia em seu banquete (PETRÔNIO. Satíricon, A ceia de Trimalquião, XXXV).

\footnotetext{
4 "Segue-se daí que, em termos bem gerais, podemos atribuir à necessidade de coerência, enquanto motor de fases diferentes do ato da leitura, o estatuto de um constituinte transcendental. Mas esta necessidade de coerência adquire em épocas diferentes e, ao que parece, também em grupos sociais diferentes, formas distintas, Justamente por isso é impossível a especificação de um modelo de leitor, transcendentemente intencionado, a ponto de se poder derivar, de sua aplicação aos textos, constantes meta-históricas da doação de sentido" (GUMBRECHT, 1977, p. 532).
} 
Percebemos, com isso, uma dualidade apresentada a partir daqueles que detinham tal saber. Mesmo que professassem benesses às vidas dos que os procuravam, os astrólogos também apreendiam o conhecimento dos infortúnios e até mesmo da morte que assolariam a pessoa que os procurou. Por isso, a relação com tais conhecedores dos segredos do Universo não foi sempre estável. Em alguns momentos, inclusive durante o Principado de Otávio, os astrólogos foram banidos de Roma, pois foram acusados de charlatanismo e de ameaçarem a paz instaurada na capital após as Guerras Civis. Agripa, por exemplo, expulsou os astrólogos em 33 a.C. (GRIMAL, 1992, p. 37).

Tal decisão foi empreendida ainda que, alguns anos antes, ambos tivessem se utilizado do saber destes "adivinhos" para comprovar a apoteose de César a partir do sinal dado por um cometa e para cunhar moedas com um novo tema que abordasse a nova era na qual Roma estava entrando, a Idade do Ouro (GRIMAL, 1992, p. 30).

Assim como aponta Katharina Volk (2009, p. 7), a vida intelectual no início do Principado foi caracterizada pela grande variedade de interesses, conhecimentos, teorias e modelos de divulgação de inúmeros saberes. Dessa maneira, a variedade de conhecimentos que formam o tema astrologia, e o ecletismo que possuía, apresenta-nos a possibilidade do interesse latente no aprendizado de tal saber. Abarca, em sua composição, não somente o estudo das estrelas por si só, mas a matemática, a geografia, a medicina, entre outros saberes. Ou seja, a astrologia, enquanto conhecimento específico, não fazia parte da formação comum a todos os cidadãos romanos, mas de um grupo bem específico que podemos identificar como elite (MARROU, 2017, p. 346-354; 445-469).

Conscientes disso, nossos autores expõem a necessidade de ensinar, o que acaba por enquadrar os textos em um gênero específico: a poesia didática. O poema didático expressa um conhecimento para alguém e, dessa forma, elege em sua composição dois personagens principais ao longo de sua narrativa: o professor, ou seja, aquele que ensina; e o aluno, a quem o ensinamento é direcionado. Tal articulação pode ser percebida pela utilização da primeira pessoa na elaboração do texto, o que nos dá a impressão de um discurso falado a alguém de maneira direta. Ao evocarem seu compromisso com a matéria e alertarem seus alunos a respeito do tortuoso caminho da aprendizagem, Lucrécio e Manílio constroem seu próprio percurso retórico a fim de legitimarem aquilo que afirmam ser necessário para o bem-estar geral.

Vejamos, primeiramente, o caso de Lucrécio. Excepcionalmente ao gênero didático, o autor referencia nominalmente a quem se dirige: Mêmio. Ao todo são onze referências diretas (LUCRÉCIO, Sobre a natureza das coisas, I: 26, 42, 411, 1052; II: 143, 182; V: 8, 93, 164, 867, 1282), desaparecendo em alguns momentos nos quais o aluno passa a ser um remetente mais impessoal. Isso não comprova que Lucrécio esqueceu a quem se dirigia, mas levanta algumas suspeitas a respeito da exclusividade do endereçamento. Lucrécio, nas palavras de Carl Joachim Classen (1968, p. 96), "mostra imediato e constante preocupação com a atenção, compreensão, julgamento, consentimento e cooperação do seu ouvinte/aluno." Em várias ocasiões, o poeta solicita que seu aluno preste atenção àquilo que está sendo dito e aceite a verdade da filosofia epicurista: 
Além de tudo, dedica à verdadeira doutrina ouvidos livres e espírito sagaz, afastado de todos os cuidados, para que, mesmo antes de as entender, não ponhas de lado, com desprezo, as minhas dádivas, para ti preparadas com fiel diligência (LUCRÉCIO. Sobre a natureza das coisas, I: 50-51). ${ }^{5}$

A dádiva preparada pelo professor libertará o aluno das amarras do medo. Lucrécio faz questão de expor, ao pedir a atenção de seu aluno, sua dedicação no preparo do material, do ensino apresentado, confirmando a urgência em ensinar ao mesmo tempo que legitima sua autoridade enquanto poeta e professor. Envolver o aluno é essencial para a efetivação de sua proposta e, por isso, a exortação se converte em recurso didático a fim de conectar quem ensina a quem aprende. Ainda no Livro I, temos mais um exemplo da atenção solicitada por Lucrécio:

Por isso, e apesar da grande demora causada pelas tuas objeções, terás de confessar que há vazio nas coisas. Posso ainda, pela menção de muitos argumentos, dar mais segurança às minhas palavras, mas a um espírito sagaz bastam estas ligeiras indicações; por elas poderás com segurança conhecer o resto. Assim como os cães, logo que dão com sinais certos de passagem, encontram muitas vezes, só pelo faro, os abrigos cobertos de folhagem dos animais que erram pelos montes, assim também, neste assunto, tu podes por ti só, explicar uma coisa por outra, penetrar por todos os recessos obscuros e de lá retirar a verdade.

Mas se fores preguiçoso e te desviares, por menos que seja, do nosso objetivo, eis o que desde já, Mêmio, te posso dizer: de tal modo, com suave linguagem, se derramarão de meu peito, cheio delas, as doutrinas que bebi em grandes fontes, que, bem o receio, a pesada velhice se insinuará pelos membros e quebrará em nós todos os liames da vida, antes que sobre um só ponto te penetre pelos ouvidos, através de meus versos, a grande cópia de argumentos (LUCRÉCIO. Sobre a natureźa das coisas, I: $398-417){ }^{6}$

Esta segunda passagem é riquíssima de detalhes que nos permitem inferir hipóteses a respeito da composição do poema didático e dos dilemas que marcam a relação entre o professor e seu aluno. O início da explicação exorta o aluno que objeta a elucidação dada, atrasando o processo de ensino. Interessante avaliar que tal objeção constatada por Lucrécio, na verdade, é um recurso retórico, pois não temos um documento escrito "a duas mãos", mas um poema desenvolvido por um professor compromissado com a matéria ensinada. Ou seja, a reação do aluno é imaginada pelo professor, que o corrige frente a uma suposição e não a uma ação verdadeiramente ocorrida.

Lucrécio não prevê tal reação do nada; ele responde àquilo que seu horizonte de expectativa projeta a partir do contexto vivido e das referências compartilhadas com Mêmio, seu aluno. Há uma fusão dos "mundos" de vida de quem escreve e de quem lê, pois compartilham interpretações possíveis a respeito de signos culturalmente formados; a obra “desperta a lembrança do já lido, [...]

\footnotetext{
5 "Quod super est, vacuas auris animumque sagacem semotum a curis adhibe veram ad rationem, ne mea dona tibi studio disposta fideli, intellecta prius quam sint, contempta relinquas."

6 "Qua propter, quamvis causando multa moreris, esse in rebus inane tamen fateare necessest. multaque praeterea tibi possum commemorando argumenta fidem dictis conradere nostris. verum animo satis haec vestigia parva sagaci sunt, per quae possis cognoscere cetera tute. namque canes ut montivagae persaepe ferai naribus inveniunt intectas fronde quietes, cum semel institerunt vestigia certa viai, sic alid ex alio per te tute ipse videre talibus in rebus poteris caecasque latebras insinuare omnis et verum protrahere inde. quod si pigraris paulumve recesseris ab re, hoc tibi de plano possum promittere, Memmi: usque adeo largos haustus e fontibus magnis lingua meo suavis diti de pectore fundet, ut verear ne tarda prius per membra senectus serpat et in nobis vitai claustra resolvat, quam tibi de quavis una re versibus omnis argumentorum sit copia missa per auris."
} 
conduz o leitor a determinada postura emocional e, com tudo isso, antecipa um horizonte geral da compreensão.” (JAUSS, 1994, p. 28).

O endereçado e sua experiência fazem parte do discurso do professor que se esforça em dar uma voz ao seu aluno. Antecipar as reações do aluno faz parte do processo poético e de ensino construído; faz de Lucrécio um atento professor às demandas de seu aluno. Imaginar possíveis intervenções como essa, expressa certo dialoguismo em que o aluno silenciado ganha espaço na construção do modelo didático. Obviamente, não podemos esquecer que, na verdade, a obra é toda construída como um monólogo, sendo a reação idealizada de Mêmio recurso importantíssimo para o compartilhamento do tema e exaltação daquele que se dispõe a compartilhá-lo; ou seja, explicar enquanto resiste-se à possível falta de paciência e interesse do aluno faz de Lucrécio alguém superior, preparado para lidar com as demandas dos menos experientes (VOLK, 2002, p. 79).

Em outras passagens, o poeta projeta reações e contra-argumentos de Mêmio, em discurso direto, introduzidos pela expressão inquis, o que constrói entendimento de participação ativa do interlocutor, como em uma sala de aula (LUCRÉCIO. Sobre a natureza das coisas, I: 803-808, 897-900). ${ }^{7}$ Mesmo assim, cabe ao professor permitir que a voz do aluno seja apresentada; em outras palavras, a voz de Mêmio é elaborada por Lucrécio: as perguntas, os contra-argumentos da pessoa que "ouvimos" não são de um personagem individual, mas provêm de uma voz construída pelo professor.

Durante o poema, o poeta continua assumindo que seu interlocutor permanece insistentemente a se dirigir ao erro e, por isso, deve preveni-lo. Como resultado, alguns autores, como Philip Mitsis (1993, p. 112), caracterizam Lucrécio pelo discurso “agressivo, tom condescendente paternalista." Difícil falarmos em tom ao analisarmos discursos escritos, mas entendemos que Lucrécio assume certa superioridade ao tratar com Mêmio sobre o que é exposto; entendemos, também, que este é mais um recurso retórico utilizado pelo autor na comprovação de sua superioridade intelectual, da importância de sua matéria - que não deve ser encarada como qualquer outro assunto e nem desprezada -, de sua autoridade literária, levando outros possíveis leitores a segui-lo sem grande questionamentos. Afinal, quem gostaria de ser comparado ao distraído Mêmio? "Com a ajuda do não tão ideal aluno intratextual, Lucrécio criou seu leitor extratextual ideal” (VOLK, 2002, p. 81). Lucrécio confirma seu conhecimento ao afirmar seu vasto estudo a respeito do tema tratado (LUCRÉCIO. Sobre a natureza das coisas, I: 400-401), mesmo que outros argumentos não fossem necessários ao aluno, que deveria, a partir do já ensinado, desvendar alguns "mistérios” por conta própria (LUCRÉCIO. Sobre a natureza das coisas, I: 402-403).

\footnotetext{
7 “'Mas' dirás tu, 'é fato inegável que todas as coisas crescem da terra para o céu e dele se alimentam; e se um tempo favorável lhes não dá chuvas, fazendo inclinar os arbustos sob a liquefação das nuvens, se, por sua parte, o sol não as aquece, lhes não dá o seu tributo de calor, não podem crescer nem as searas, nem as plantas arbóreas, nem os animais." // “'At manifesta palam res indicat' inquis 'in auras aeris e terra res omnis crescere alique; et nisi tempestas indulget tempore fausto imbribus, ut tabe nimborum arbusta vacillent, solque sua pro parte fovet tribuitque calorem, crescere non possint fruges arbusta animantis."'; "Mas', dirás tu, 'acontece muitas vezes, nos altos montes, que as árvores mais elevadas rocem os cimos uns pelos outros, sob o ímpeto dos austros violentos, até que a flor do fogo rebente e flameje."'//“'At saepe in magnis fit montibus' inquis 'ut altis arboribus vicina cacumina summa terantur inter se validis facere id cogentibus austris, donec flammai fulserunt flore coorto."”
} 
A comparação realizada pelo poeta, ao denotar a autossuficiência de seu aluno, não é lisonjeira: Mêmio deveria caminhar pela estrada do aprendizado, entendendo aquilo que seu professor não explicitaria, assim como um cão que encontra abrigo apenas pelo faro; ou seja, o professor rebaixa o aluno ao compará-lo ao animal, exortando-o para que cumpra com suas obrigações (LUCRÉCIO. Sobre a natureza das coisas, I: 404-409).

O leitor/aluno é encarado como alguém "ingênuo" que, assim como uma criança, está preso aos seus prazeres e, por isso, deve ser atraído pelo doce mel da poesia, sendo capaz de "tomar" o amargo remédio do Epicurismo. Tal recurso é constantemente utilizado pelo poeta, que compara todos os que não seguem a verdade epicurista a crianças "que tremem no frio" (MARKOVIC, 2008, p. $30) .8$

A "ingenuidade" de Mêmio frente ao ensinamento tão importante tem um limite. Não seria interessante desestimular o aluno a partir de represálias duras demais. A incapacidade atestada poderia afastar completamente o aluno que, ao perceber a dificuldade do percurso, desistiria - e não é esse o interesse de Lucrécio. O poeta deseja se aproximar, e ser lido, pela elite romana (pressuposto afirmado anteriormente) e, por isso, reconhece, em seu "diálogo" com o aluno, a capacidade deste de preencher os vazios deixados pela explicação. Mesmo que a comparação com um cão não enalteça ou valorize Mêmio, há uma crença depositada pelo professor. que acredita ser seu aluno capaz de seguir pelo caminho esperado (LUCRÉCIO, Sobre a natureza das coisas, I: 407-409). Tal confiança só seria possível se houvesse um conhecimento prévio do aluno a respeito do tema tratado: o Epicurismo, neste caso; e a filosofia não participava do currículo comum de todo cidadão romano, sendo apreendida apenas pela elite que se disponibilizava ao estudo e dedicava-se aos ensinos que elevavam a alma (GRIMAL, 2017, p. 83).

A "brevidade" do assunto é um recurso retórico utilizado por Lucrécio a fim de estimular a busca do aluno pela matéria, insinuando seu conhecimento prévio acerca do tema proposto. Além disso, não podemos ignorar que abreviar explicações serve também para que o poeta alcance seu objetivo ao confeccionar sua obra, aliando saber/ensinar à beleza necessária. Tal prática não concerne apenas à análise de Sobre a natureza das coisas, mas também à obra maniliana, o que acaba por estabelecêlas dentro do contexto de grande produção literária:

Para que o seguinte método também não te engane, aprende por meio de poucas palavras - o menor é maior em efeito - quão pequena é, dentre as partes mesmas da dodecatemória, aquela que é também dita dodecatemória. Com efeito, ela se divide em cinco partes, pois no céu brilha um mesmo número de estrelas que são ditas errantes e que recebem, cada uma delas, meio grau, assumindo nele suas forç̧as e sua autoridade. Convirá, pois, observar em qual dodecatemória e em que momento cada planeta está localizado; pois um planeta produzirá seus efeitos sob as influências daquela dodecatemória dentro de cujos limites, qualquer que seja o signo, ele se encontrar. Deve-se buscar a todas as partes a combinação pela qual tudo está estabelecido. Entretanto, essa matéria toda apresentarei posteriormente,

\footnotetext{
8 Outras referências: LUCRÉCIO. Sobre a natureza das coisas, III: 87-93; VI: 35-41; LUCRÉCIO. Sobre a natureza das coisas, II: 55-59.
} 
conforme a ordem apropriada; basta, por ora, ter ensinado coisas ainda não conhecidas, demonstrando-lhes os usos, de modo que, quando tua confiança se tiver tornado firme mediante a compreensão das partes, seja notado, então, com fácil raciocínio, o conjunto inteiro, e convenientemente venha, enfim, depois do trato com as partes, o poema sobre o todo. Assim como às incultas crianças primeiro se mostra a letra, com sua forma e seu nome, e em seguida se lhes explica seu uso, depois se forma a sílaba, unida por suas letras, daí vem a construção da palavra, que se deve ler de acordo com suas partes componentes, depois é ensinada a força das expressões e os usos da arte gramática, e, formando-se em pés apropriados, os poemas se constroem, e é proveitoso ter aprendido cada uma das coisas primeiras (se estas não se tiverem estabelecido firmemente, fundadas sobre os primeiros elementos, cairá no vazio, atrapalhada, a ordem das coisas, e se acharão desarranjados os preceitos que os mestres tenham dado às pressas), assim também, por mim, a voar pelo céu inteiro com meu poema e a cantar os destinos arrancados ao fundo da impenetrável escuridão, modulados pelo ritmo das Piérides, e a invocar para minha arte o poder com que o deus reina, por mim deve ser conquistada também em partes a confiança, e cada uma das coisas deve ser relacionada a suas partes especificas, de modo que, quando todas as coisas estiverem estabelecidas com uma firme compreensão, possam ser referidas a seus usos particulares. Como quando se erguem cidades sobre nuas montanhas, e seu construtor almeja circundar com muros as colinas vazias, antes que sua mão tente abrir os fossos, trabalhou-se com empenho (eis que um bosque rui, e florestas antigas sucumbem e veem o Sol, até então desconhecido, e as estrelas, até então desconhecidas; toda raça de aves e de animais é repelida de seu lugar, abandonando suas antigas casas e tão bem conhecidos ninhos; outros, entretanto, procuram pedras para paredes e mármore para templos, e por meio de sinais conhecidos o duro ferro é por eles procurado; de um lado as artes, de outro toda prática se combinam); a construção só tem início quando todas as coisas preliminares estão à disposição, a fim de que um cuidado desordenado não interrompa o trabalho ao meio do caminho, do mesmo modo, por mim, que me esforço por tomar tão grande empresa, deve primeiro ser apresentada a matéria dos assuntos, deixando-se de lado a explicação, a fim de que tal explicação não se mostre inútil depois, e meus argumentos, ao se formarem, não se calem diante de pontos ainda não mostrados. ${ }^{9}$ (MANÍLIO. Astronômicas, II: 738-787)

O poeta se delonga ao descrever o seu método didático, "fundamentado na exposição progressiva da matéria, cuja graduação ele compara ao processo de instrução das crianças (MANíLIO. Astronômica, II: 255-287)" (FERNANDES, 2012, p. 245). Evocamos, mais uma vez, Horácio, que explica a respeito da brevidade necessária na elaboração do discurso poético (HORÀCIO, Arte Poética, 335). Porém, argumenta que a brevidade não deve ser realizada de forma indiscriminada, mas

\footnotetext{
9 "Haec quoque te ratio ne fallat, percipe paucis (maior in effectu minor est) de partibus ipsis dodecatemorii quota sit quod dicitur esse dodecatemorium. namque id per quinque notatur partes; nam totidem praefulgent sidera caelo quae uaga dicuntur, ducunt et singula sortes dimidias, uiresque in eis et iura capessunt. in quo quaeque igitur stellae quandoque locatae dodecatemorio fuerint spectare decebit; cuius enim stella in fines in sidere quoque inciderit, dabit effectus in uiribus eius. undique miscenda est ratio per quam omnia constant. Uerum haec posterius proprio cuncta ordine reddam; nunc satis est docuisse suos ignota per usus, ut, cum perceptis steterit fiducia membris, sic totum corpus facili ratione notetur et bene de summa ueniat post singula carmen. ut rudibus pueris monstratur littera primum per faciem nomenque suum, tum ponitur usus, tum coniuncta suis formatur syllaba nodis, hinc uerbi structura uenit per membra legendi, tunc rerum uires atque artis traditur usus perque pedes proprios nascentia carmina surgunt, singulaque in summam prodest didicisse priora (quae nisi constiterint primis fundata elementis, effluat in uanum rerum praeposterus ordo uersaque quae propere dederint praecepta magistri), sic mihi per totum uolitanti carmine mundum erutaque abstrusa penitus caligine fata, Pieridum numeris etiam modulata, canenti quoque deus regnat reuocanti numen in artem, per partes ducenda fides et singula rerum sunt gradibus tradenda suis, ut, cum omnia certa notitia steterint, proprios reuocentur ad usus. ac, uelut, in nudis cum surgunt montibus urbes, conditor et uacuos muris circumdare colles destinat, ante manus quam temptet scindere fossas, feruit opus (ruit ecce nemus, saltusque uetusti procumbunt solemque nouum, noua sidera cernunt, pellitur omne loco uolucrum genus atque ferarum, antiquasque domos et nota cubilia linquunt, ast alii silicem in muros et marmora templis rimantur, ferrique rigor per pignora nota quaeritur, hinc artes, hinc omnis conuenit usus), tum demum consurgit opus, cum cuncta supersunt, ne medios rumpat cursus praepostera cura, sic mihi conanti tantae succedere moli materies primum rerum, ratione remota, tradenda est, ratio sit ne post irrita neue argumenta nouis stupeant nascentia rebus."
} 
observando com cuidado a compreensibilidade daquilo que é dito; assim feito pelo poeta, aquele que aprende conseguirá reter o conteúdo importante, permitindo que sua mente não transborde com superficialidades (HORÁCIO. Arte Poética, 337 - omne superuacuum pleno de pectore manat).

Diskin Clay (1983, p. 225) analisa esses espaços vazios, argumentos não finalizados, deixados por Lucrécio, que confia em seu interlocutor para preenchê-los. Há uma recusa em argumentar mais, já que, de acordo com o poeta, vestígios suficientes foram apresentados, sendo o aluno capaz de desvendar o resto sozinho. A poesia deveria render prazer não apenas a quem escreve, mas também a quem lê; prazer que não se relaciona apenas com a apreciação estética do conteúdo, mas ao entendimento da matéria filosófica proposta. A poesia seria prazerosa para o poeta porque beneficia o leitor, pois o prazer que este experimenta no processo de leitura permite que o conteúdo filosófico salubre faça seu efeito (GALE, 2007, p. 73). Para Quintiliano, aquilo que se divulga deve ser feito em ordem concisa para que não seja divulgado o supérfluo (Instituição Oratória, IV: 2.42). Ao mencionar a distinção que "alguns gregos" (graecorum aliqui) realizam entre "exposição concisa" (circumcisam

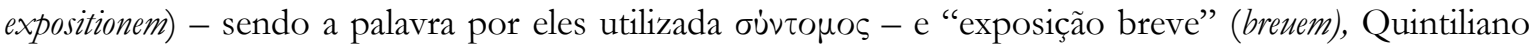
estabelece que a brevidade ${ }^{10}$ consiste em "não dizer menos, mas em não dizer mais do que é necessário" (QUINTILIANO. Instituição Oratória, IV: 2.43). ${ }^{11}$

Como já exposto, a "brevidade" não foi recurso utilizado apenas por Lucrécio, mas também por Manílio que chama a atenção de seu aluno para que as breves palavras não ocultem o grande proveito em compreender a matéria ensinada (MANÍLIO. Astronômicas. III: 275-277); a utilização das "breves palavras" (compendia dictis) "comporta o risco da obscuridade" (FERNANDES, 2012, p. 254) e, por isso, a atenção do aluno é fundamental.

Tal jogo retórico de diálogo entre o autor e interlocutores idealizados não é uma exclusividade do gênero didático. Assim como aponta Longinus (Sobre o sublime, XVIII: 77), tal recurso é de grande valia na legitimação da argumentação realizada; cabe ao poeta construir tal interação da melhor maneira possível a fim de "esconder" que as objeções projetadas na "pseudo fala" do aluno na verdade são suas, conseguindo acentuar não só a sublimidade de suas próprias palavras, mas tornando-as mais convincentes. E mesmo não sendo recurso exclusivo ao gênero didático, esse tem papel essencial na construção poética e, quando unido a outras várias características, imprime uma apresentação ímpar ao que se apresenta. A persona discipuli participa do diálogo a partir do que a persona doctoris espera, sendo esta característica reconhecida por Katharina Volk enquanto "constelação professor-aluno" (2002, p. 37) - importantíssima para a realização de nossa análise.

O poeta, de acordo com Horácio, ensina e cabe aos que leem procurar deleite enquanto também aprendem (HORÁCIO. Arte Poética, 343-344).12 Mesmo que este seja um compromisso de

\footnotetext{
${ }^{10}$ Sobre a seleção daquilo que deve ser dito: "Em terceiro lugar temos o pensamento, que consiste na capacidade de dizer o

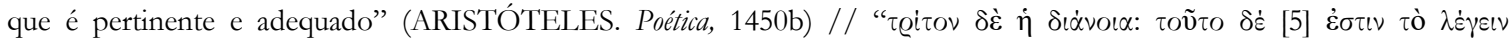

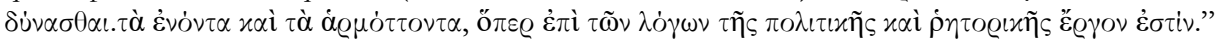

11 "breuitatem in hoc ponimus, non ut minus sed ne plus dicatur quam oporteat."

12 "omne tulit punctum, qui miscuit utile dulci lectorem delectando pariterque monendo."
} 
todo bom poeta, há especificidades que fazem nossos autores participantes de um grupo específico: aqueles que desenvolveram poesias didáticas.

Manílio também "dialoga" com seu aluno, porém não sabemos a quem se dirige especificamente. Uma combinação entre conhecimento teórico acerca do cosmo e conselhos astrológicos de ordem pessoal na busca do aluno em conhecer as previsões do destino marca a relação entre esses personagens (autor e leitor/ professor e aluno), mesmo que não haja endereçamento específico; porém percebemos que os conselhos ministrados se tornam mais frequentes quando Manílio apresenta assuntos práticos e cálculos, a exemplo da explicação sobre o horóscopo no Livro III (498-682). A falta de identificação do aluno, e a necessidade de alguns pesquisadores de nomeá-lo, acabou por ocupar boa parte das poucas análises feitas a respeito do autor e de sua obra. Uma das hipóteses levantadas apresenta Otávio como aquele que recebe o ensinamento, graças às constantes referências ao Imperador (MANíLIO. Astronômicas, I: 7-10, 384-386, 925-926; II: 507-510; IV: 547-52, 763-766, 773-777). Tal interpretação se suporta no interesse reconhecido de Otávio sobra astrologia, saber que se desenvolveu bastante na passagem da República para o Império graças à proximidade desse com os assuntos políticos do período (BARTON, 1994, p. 38). Porém, percebemos um outro papel atribuído ao Princeps que não o de aluno: o de homenageado (reconhecido, inclusive, como um herói). Fazemos tal afirmação pois Manílio não direciona nenhum conselho a Otávio, atribuindo-lhe apenas elogios. Reconhecemos ser esse um processo comum a outros escritores que se dedicaram a escrever neste mesmo período. Como aponta E. Pöhlmann (1973, p. 863-865), tal "função elogiosa" pode ser encontrada em Virgílio (Geórgicas, I: 24-42) e Ovídio (Fastis, I: 1-26), confirmando, em certa medida, a posição de Otávio enquanto homenageado na obra maniliana.

Mesmo que não seja um aluno nominalmente conhecido, Manílio se dirige a alguém. Entendemos que, provavelmente, o público quisto pelo poeta fosse muito maior do que apenas um aluno, apesar de, ao se dirigir ao seu interlocutor, utilizar constantemente o emprego da segunda pessoa do singular. Ainda assim, não identificamos uma relação pessoal/próxima entre estes dois personagens, como podemos inferir na situação de Lucrécio e Mêmio. O que podemos apreender é a existência de um público específico ao qual Manílio quer alcançar - do qual o poeta deseja atenção: "Aproxima-te, ó quem quer que sejas, que possas aplicar ouvidos e olhos à minha empresa, e ouve as palavras verdadeiras. Presta atenção, e não procures doces carmes” (MANíLIO. Astronômicas, III: 3638). ${ }^{13}$

A exortação ao aluno para que preste atenção e procure a verdade é uma característica básica da poesia didática. Ao iniciar sua chamada, Manílio aparenta estar se dirigindo a um público vasto, a qualquer um que se interesse pelo tema, a partir do emprego do pronome indefinido quincunque (VOLK, 2002, p. 203); porém, ao conclamar aqueles para que possam "aplicar ouvidos e olhos", o

\footnotetext{
13 "Huc ades, o quicumquue meis advertere coeptisaurem oculosque potes, veras et percipe voces. Impendas animum; nec dulcia carmina quaeras."
} 
poeta define que possivelmente existiriam os que não poderiam assim fazê-lo. Dessa maneira, quem seria, então, o público/aluno esperado? A resposta, aparentemente, encontra-se no Livro II:

Tais são as coisas que com um sopro divino eu gostaria de levar até às estrelas, e não na turba nem para a turba comporei o meu poema, mas sozinho, como se, levado numa órbita desimpedida, livre eu impelisse os meus carros sem ninguém a obstruir-me a passagem nem a dirigir seu movimento paralelamente ao meu por um caminho comum ao meu; cantarei coisas tais, que o céu as reconheça, com os astros a admirarem-se e o firmamento a regozijar-se com o poema de seu vate; cantarei, ainda, para aqueles a quem os astros não recusaram os sagrados canais e o conhecimento deles mesmos, que formam a menor sociedade no mundo. ${ }^{14}$ (MANÍLIO. Astronômicas, II: 136-149)

Nem todos poderiam acompanhar sua explicação, como o trecho acima deixa claro. A audiência esperada seria exclusiva e restrita para pessoas que pudessem seguir o professor enquanto expõe a verdade, um pequeno grupo que tem a habilidade necessária, já que seus componentes foram agraciados pelo cosmo com a clareza de pensamento. Pequeno grupo, todos os homens, o público maniliano parece não ter um limite estabelecido quando analisamos outras passagens da obra:

Quem, em vista dessas coisas, hesitaria em ligar ao céu o homem, ao qual, desejando que a terra se elevasse até às estrelas, dádiva distinta natureza deu, bem como a língua, e a ampla inteligência, e um espírito alado, único, afinal, em que o deus desceu e habita, e a si mesmo ele próprio busca? ${ }^{15}$

Que há de admirar se os homens podem conhecer o céu, se neles próprios está o céu e cada um é uma cópia do deus numa imagem pequena? É certo acreditar que o homem veio de algum outro lugar que não o céu?

$[\ldots]$

O céu mesmo chama as nossas atenções para as estrelas e, como não oculta os poderes que tem, não admite que passem despercebidos.

(MANÍLIO. Astronômicas, II: 105-108; IV: 893-897, 920-921). ${ }^{16}$

Uma contradição estabelecida: Manílio ensina a pequena turba de inspirados pelo próprio cosmo ou a todos os homens, pois são componentes do deus que é o Universo? Não há como confirmar nenhuma das hipóteses levantadas, o que nos aproxima da explicação dada por Volk (2002, p. 208), que considera a relação professor-aluno na obra maniliana como, também, uma técnica retórica em que não há preocupação do autor em manter a coerência, ao menos não desse ponto, daquilo que apresenta. O que almeja Manílio é enaltecer o seu trabalho dando espaço ao aluno quando

\footnotetext{
14 "Haec ego divino cupiam cum ad sidera flatu ferre, nec in turba nec turbae carmina condam sed solus, vacuo veluti vectatus in orbe liber agam currus non occursantibus ullis nec per iter socios commune regentibus actus, sed caelo noscenda canam, mirantibus astris et gaudente sui mundo per carmina vatis, vel quibus illa sacros non invidere meatus notitiamque sui, minima est quae turba per orbem. Illa frequens, quae divitias, quae diligit aurum, imperia et fasces mollemque per otia luxum et blandis diversa sonis dulcemque per aures affectum, ut modico noscenda ad fata labore. hoc quoque fatorum est, legem perdiscere fati."

15 "quis dubitet post haec hominem coniungere caelo, cui, cupiens terras ad sidera surgere, munus eximium natura dedit linguamque capaxque ingenium volucremque animum, quem denique in unum descendit deus atque habitat seque ipse requirit?"

16 "Quid mirum, noscere mundum / si possunt homines, quibus est et mundus in ipsis / exemplumque dei quisque est in imagine parua? an cuiquam genitos, nisi caelo, credere fas est esse homines? [...]. Ipse uocat nostros animos ad sidera mundus / nec patitur, quia non condit, sua iura latere."
} 
necessita de atenção ao que está sendo ensinado. $O$ poeta estende seu sentimento elitista ao interlocutor em uma linguagem de iniciação quase religiosa, mas, ao mesmo tempo, seu trabalho deve ser entendido como essencial a toda humanidade. Ele não quer ser desprezado. Talvez, o único critério de seleção estabelecido seja a disposição do próprio aluno em aprender, desprezando os prazeres que o distraem do conhecimento (MANÍLIO. Astronômicas, II: 145-149).

Assim como não cabe ao professor ser apenas um canal inerte a respeito do saber astrológico (ele deve interpretar o conhecimento e atrair o interesse do seu aluno), não cabe ao aluno a passividade frente ao ensino ministrado; “cumpre ao discípulo não só preferência pela 'lição verdadeira' [...] mas [...] esforço no trabalho de intelecção" (FERNANDES, 2012, p. 261). E o aluno que segue pelo caminho do aprendizado junto aos seus professores recebe como prêmio, como compensação, as palavras verdadeiras. ${ }^{17}$ Porém, para alcançar tamanha dádiva, professor e aluno devem se esforçar. Assim como compete a Manílio cantar o destino, cabe ao aluno estudar com "profunda inteligência" (Astronômicas, IV: 308 - alta sed mente). As fórmulas e expressões utilizadas pelos poetas (Manílio e Lucrécio), a fim de terem a atenção do aluno/leitor, não fogem do padrão estabelecido ao gênero da poesia didática (percipe paucis e percepi dicta - LUCRÉCIO. Sobre a natureza das coisas, IV: 115, 480, 723; percepi mente e percepi noces - MANÍLIO. Astrônomicas, II: 927, III: 37), o que comprova a existência de uma tradição literária compartilhada, ao mesmo tempo que, provavelmente, a obra lucreciana foi um modelo para Manílio desenvolver seu manual didático astrológico.

O labor ao qual o aluno é condicionado demonstra o ápice civilizacional alcançado ao longo do tempo. A racionalidade empregada para a compreensão da matéria (seja pela ratio divina maniliana ou pela liberdade racional epicurista defendida por Lucrécio) faz dos trabalhos realizados pelos professores e por seus alunos fonte de prazer - "o labor é proporcional ao prêmio" (MANíLIO. Astronômica, IV: 393). ${ }^{18}$

Vale ressaltar que as abordagens de Lucrécio e Manílio aos seus alunos não constituem-se apenas de semelhanças. Matt Neuburg (1993, p. 257) percebeu que, enquanto Manílio encoraja constantemente seu aluno a partir de um esforço necessário para o sucesso, Lucrécio antecipa os erros, cansaços e distrações de Mêmio, exortando-o mais do que encorajando-o. Mesmo assim, os tratamentos realizados se enquadram na elaboração da constelação professor-aluno, característica essencial do gênero poético didático.

Temos consciência de que o ato de ensinar é uma característica comum a vários estilos literários na Antiguidade, assim como o estabelecimento de diálogo entre quem escreve e um pretenso leitor (confirmação de autoridade e legitimação das ideias divulgadas) e, por isso, sabemos que tais características não são suficientes para a identificação de um gênero tão específico quanto a poesia didática. Ou seja, obras diversas poderiam conter ensinamentos necessários para a manutenção da

\footnotetext{
17 Assim como para o aluno de Lucrécio a verdade alcançada se torna o prêmio obtido; prêmio esse que consiste na vida sem medo diante da religio (LUCRÉCIO. Sobre a natureza das coisas, I: 62-79).

18 "pro pretio labor est..."
} 
ordem social ou, inclusive, a respeito de temas tidos como técnicos (assim como a astrologia). Assim são as obras Sobre a Agricultura, de Catão Censor (séculos III a II a.C.), e Sobre a vida rústica, de Varrão. A própria obra horaciana Arte Poética também traz uma série de ensinamentos a respeito da produção literária e, ainda assim, não se enquadra no gênero didático, como as obras maniliana e lucreciana. Nas palavras de Matheus Trevizam, "nem todo texto greco-romano de 'tom' professoral, mesmo que escrito em versos, cabe classificar-se desta maneira" (TREVIZAM, 2014, p. 22).

Tal constatação se faz necessária, pois hoje possuímos o hábito de classificar tudo a partir dos pormenores e diferenças, separando em "diversas caixas" os vários conhecimentos humanos. Assim sendo, estranhamos a formação de textos poéticos que também possuem como função a divulgação de saberes específicos e, em certa medida, técnicos a respeito de temas considerados por nós "não tão poéticos assim." Ainda somos formados pelo signo científico de formação do conhecimento verdadeiro que separa em tipos de textos adequados ao intento da divulgação acadêmica/intelectual. Mas temos que lembrar que o homem antigo assim não pensava (mesmo que a discussão sobre verdade no discurso já fosse realizada); durante o Império, pontua Pierre Grimal (1984, p. 268), "eram raros os romanos cultos que não alimentavam ambições literárias." A vida "intelectual" não estava presa às cátedras, distante das ruas; estava presente nas conversas, na educação e em diversas atividades sociais. Devemos lembrar, ainda, como pontua Gilvan Ventura da Silva (2001), que poetas como Manílio e Ovídio fizeram parte da formação e construção da opinião pública, uma vez que, na Antiguidade, os poetas cumpriam papel moralizante e pedagógico justamente por reterem e propagarem os feitos grandiosos de governantes, de tradições e de costumes ancestrais. Tal importância pode ter sido atribuída à ars poetica, especificamente ao gênero didático abordado neste texto, justamente pelo fato de tais feitos terem a possibilidade de cair, facilmente, no esquecimento. Não à toa, as obras literárias eram pensadas para a leitura pública, as recitationes, "moda" esta lançada, ainda de acordo com Grimal, por Asínio Pólio durante o período augustano. Inicialmente, as conferências públicas estavam ligadas ao discurso filosófico; posteriormente, já identificamos a divulgação de outros saberes e estilos.

A poesia didática assim se fez presente. Podemos estranhar a composição de um poema a respeito do conhecimento astrológico, por exemplo, mas para o homem romano isto não seria um problema: "A não separação entre estética e a ética é característica do pensamento grego primitivo" (JAEGER, 2003, p. 61-62), sendo o processo de separação entre elas relativamente tardio.

Não há referência direta ao gênero "poesia didática" no período analisado neste trabalho. As primeiras referências, como destaca Matheus Trevizam (2014, p. 25), aparecem entre os séculos IV e V d.C.. A obra do grammaticus Diomedes, Ars Grammatica, em diálogo com a tradição platônica, distingue tipos poéticos conforme os modos de discurso adotado: poesia "dramática", poesia "narrativa", e poesia "mista". Seria nesta natureza literária mista que surge a poesia didática; uma junção de dramaticón (termo grego incorporado por Diomedes) e enarratiuum. É a partir desta distinção que outras três subcategorias surgem: angeltice, historice e didascalice, sendo esta última a categoria em que nossos autores 
se encontrariam: "A poesia didática é o modelo ao qual se apresenta a filosofia de Empedocles e Lucrécio, assim como a astronomia dos Fenômenos, de Arato e Cícero, e As Geórgicas, de Virgílio, entre outras (DIOMEDES. Arte Gramática, 483. 1-3). ${ }^{19}$

Tal explicação acaba por confirmar a separação entre o épico e a poesia didática, confundidas pela formatação poética em hexâmetros. O termo grego didásco pode ser compreendido como "ensinar", "instruir" e, por isso, a subcategoria didascalice de Diomedes foi traduzida por nós como poesia didática. Já no século $\mathrm{X}$ temos mais uma obra, de autoria desconhecida, Tractatus Coislinianus, que propõe uma separação em tipos poéticos, sendo eles os "miméticos" - narrativas e teatro - e os "não miméticos" - divididos em historiké e paideutiké (poesia que instrui).

Mesmo que estas definições sejam posteriores, Trevizam destaca que algumas características de obras temporalmente distantes devem receber tratamento evidente a fim do estabelecimento do gênero poético didático; em outras palavras, obras gregas e romanas carregavam características específicas quanto à organização dos temas propostos, o que permitiu aos historiadores identificarem uma poesia que ensina:

\begin{abstract}
Havia códigos literários que marcavam a distinção genérica. O mais óbvio deles era recorrer à autoridade de Hesíodo, o prôtos heurêtês do gênero. Arato é louvado por Calímaco por seguir o tema e o modo de Hesíodo (Epigrama 29.1). Virgílio descreve as Geórgicas como o "canto de Ascra" (2.176), e suas palavras são posteriormente ecoadas por Columela. Nicandro invoca o testemunho de "Hesíodo de Ascra" perto do início de seu poema sobre serpentes venenosas. Era uma prática comum entre os poetas latinos indicar suas aflições literárias no início das obras com um aceno cordial para seus predecessores. Manílio abriu sua obra com a tradução da primeira linha da Teogonia de Hesíodo. Essas referências sugerem uma sucessão apostólica de poetas didáticos conscientes de seus elos genéricos comuns e que se veem como continuadores de uma tradição que remonta a Hesíodo. Não seria verdadeiro, então, dizer que a literatura clássica não reconhecia a existência da poesia didática como um gênero distinto (DALZELL, 1996, p. 21-22).
\end{abstract}

Existiu, então, uma tradição de textos organizados diferentemente dos outros modelos já estabelecidos pelas teorias aristotélica e platônica. Desde Hesíodo até nossos autores, há um esforço em perpetuar uma forma específica para alcançar um objetivo específico também; e é a partir disto que escapamos do total anacronismo em nossa definição do gênero, pois, mesmo que não houvesse o reconhecimento da poesia didática em si, visível é o esforço de fundamentar uma outra categoria de composição em grande medida diferente das demais formas literárias antigas (TREVIZAM, 2014, p. 29). Ainda que retomemos Aristóteles enquanto modelo explicativo, contemos já em sua abordagem dificuldade em classificar obras que, posteriormente, seriam denominadas dentro do gênero didático. Ao falar da obra de Empedocles, o filósofo alega que este não pode ser chamado de poeta, pois a única semelhança entre sua obra e a de Homero, por exemplo, é a métrica; o tema apresentado pelo primeiro não se enquadra na composição poética a partir da mimese aristotélica e, por isso, seria Empedocles um naturalista (ARISTÓTELES. Poética, 1447b. 15-20).

\footnotetext{
19 "didascalice est qua comprehenditur philosophia Empedoclis et Lucreti, item astrologia, ut phanomena Aratu et Ciceronis, et georgica Vergilii et his simila."
} 
Tanto a compreensão apenas pela mimese quanto pelo tema apresentado, ou apenas pela métrica utilizada, não nos permitiria, de fato, conceber o gênero didático na Antiguidade romana. Por isso que, por algum tempo, ponderou-se em subcategorizá-lo como uma ramificação do épico, especificamente pela sua composição em metro de hexâmetros datílico (sendo exceções as obras ovidianas Ars amatoria e Remedia amoris, compostas em dísticos elegíacos). Peter Toohey (2010, p. 5) não considera a poesia didática enquanto um gênero específico, distinto dos demais modelos encontrados no mundo greco-romano. Em sua alegação, o autor afirma que não existiam regras fixas estruturais para a composição literária no mundo romano, sendo trabalho do escritor selecionar, dos vários estilos existentes, material pertinente. O próprio Lucrécio apresenta algumas referências para a composição de sua obra,

[...] como cantou o romano Énio, que foi o primeiro a trazer do ameno Hélicon uma coroa de perene folhagem, cuja glória se espalharia entre as gentes de Itália. No entanto, Ênio também claramente expõe, em versos eternos, "que há lugares certos do Aqueronte onde ficam, não as nossas almas e os nossos corpos, mas umas como sombras de estranha palidez"; e diz que de lá lhe falou da natureza das coisas, depois de haver derramado lágrimas amargas, o sempre glorioso Homero. (LUCRÉCIO. Sobre a natureza das coisas, I: 117-126)..$^{20}$

Lucrécio realiza uma clara referência à tradição literária de seu tempo ao citar Homero e Ênio como predecessores, ambos identificados como "gênios" do épico grego e latino, respectivamente. Por isso, Lucrécio estaria, então, se reconhecendo enquanto um escritor épico mesmo diante das imensas diferenças temáticas? Acreditamos que a intenção não tenha sido essa, mas a de se apresentar dentro de uma tradição, estabelecendo, com isso, a autoridade literária almejada. Assim como afirma Monica Gale (2007, p. 61), Lucrécio se apresenta implicitamente como herdeiro de três grandes escritores (os dois que já citamos acima e Empedocles); ao mesmo tempo, o poeta critica explicitamente seus antecessores (Ênio, pela sua fonte trabalhada; Homero e sua confusão a respeito da vida após a morte; e Empedocles, pelos erros de suas teorias físicas (LUCRÉCIO. Sobre a natureza das coisas, I: 716), realizando a aemulatio destes modelos, imitando-os e superando-os no que se faz necessário. ${ }^{21}$ Argumenta Markovic (2008, p. 33):

Lucrécio molda sua persona professoral com a ajuda de Homero, Ênio e Epicuro. Essa complexa linhagem endossa-o com absoluta autoridade. Apenas com tamanha autoridade seria possível alcançar o objetivo do poema, o que era de compor a única verdade possível sobre todo o Universo.

Outras referências podem ser percebidas, assim como D. P. Fowler (2000, p. 144) aponta ao analisar a passagem do Livro I (250-261), na qual o poeta se utiliza da imagem do casamento entre o Céu e a Terra, aproximando-se do texto trágico de Eurípedes; assim como elementos do gênero lírico

\footnotetext{
20 "Ennius ut noster cecinit, qui primus amoeno detulit ex Helicone perenni fronde coronam, per gentis Italas hominum quae clara clueret; etsi praeterea tamen esse Acherusia templa Ennius aeternis exponit versibus edens, quo neque permaneant animae neque corpora nostra, sed quaedam simulacra modis pallentia miris; unde sibi exortam semper florentis Homeri commemorat speciem lacrimas effundere salsas coepisse et rerum naturam expandere dictis."

${ }^{21}$ Para mais referências, ver Brown (2007, p. 330).
} 
e epigramas, o que confirma a tese de que não havia limite estilístico rígido para o romano que desejasse escrever. Lucrécio não teria desenvolvido um poema épico por abordar, em suas próprias palavras, um tema técnico demais e difícil ao tratamento em versos latinos (LUCRÉCIO. Sobre a natureza das coisas, I:136-139), o que, na explicação aristotélica, o excluiria deste modelo tão apreciado por gregos e romanos.

Ainda que as obras estudadas sejam compostas de elementos intratextuais diversos, elas devem ser identificadas enquanto poesias didáticas, pois os elementos presentes, e dispostos como estão, compõem diferença considerável aos outros textos os quais servem de inspiração.

Assim sendo, mesmo que as obras analisadas não tenham sido classificadas como "poesia didática" pelos próprios autores, o estudo comparativo com outras obras por estes citadas e referenciadas, direta ou indiretamente, nos possibilitam afirmar a existência de um modelo diferenciado de outros tantos. Para além da missão de ensinar, Manílio e Lucrécio constroem processos de escrita que implicam a existência de compromissos moral e estético para com seu interlocutor. Mesmo que outras obras também acabem por "ensinar" algo a alguém, os poemas em questão destacam tal missão a partir da clara alusão ao papel do professor e de seu público (os alunos), além de apresentarem, concomitantemente, a importância daquilo que é ensinado. Lucrécio pretende livrar o homem do medo a partir de seu poema epicurista, e Manílio restaurar a República a partir do governo augustano, ensinando sobre os astros e a respeito da inexorabilidade do destino salvaguardado nas estrelas. É a crise republicana vivida e solucionada pelos autores que sentem de seus possíveis leitores a necessidade de respostas ao tempo vivido. É a beleza poética que adoça conteúdos tão difíceis, e importantes, que faz da empreitada de nossos autores algo possível.

\section{REFERÊNCIAS}

ARISTÓTELES. Poética. Trad. Paulo Pinheiro. São Paulo: Editora 34, 2015.

BARTON, T. Astrology and the State in Imperial Rome. In: HUMPHREY, Caroline; THOMAS, Nicholas (ed.). Shamanism, History, and the State. University of Michigan Press, 1994, p. 146-163.

BROWN, R. D. Lucretius and Callimachus. In: GALE, Monica R. (org.). Lucretius: Oxford Readings in Classical Studies. New York: Oxford University Press, 2007.

CASSON, L. Bibliotecas no mundo antigo. São Paulo: Vestígio, 2018.

CICERO. Letters to Quintus and Brutus. Letter Fragments. Letter to Octavian. Invectives. Handbook of Electioneering. Trad. D. R. Shackleton Bailey. Harvard: Harvard University Press, The Loeb Classical Library, 2002.

CICERO. On Ends. Trad.: H. Rackham. Harvard: Harvard University Press, 1914. (Loeb Classical Library). 
CLASSEN, C. J. Poetry and rhetoric in Lucretius. Transactions and Proceedings of the American Philological Association. Johns Hopkins University Press, American Philological Association, v. 98, p. 77-118, 1968.

CLAY, D. Lucretius and Epicurus. Ithaca, New York: Cornell University Press, 1983.

DALZELL, A. The criticism of didatic poetry: Essays on Lucretius, Virgil and Ovid. Toronto; Búfalo; Londres: University of Toronto Press, 1996.

DIOMEDES. Diomedis Ars. In: KEIL, H. (ed.). Grammatici Latini, I, 299-529. Leipzig: Teubner, $1855-$ 1880 [repub. Hildesheim: Olms, 1981].

FERNANDES, M. V. As faces da razão: instrução e mimese nas Astronômicas de Manílio. Tese (Doutorado em Letras Clássicas e Vernáculas) - Faculdade de Filosofia, Letras e Ciências Humanas, Universidade de São Paulo, São Paulo, 2012.

FOWLER, D. P. The Didactic Plot. In: DEPEW, M.; OBBINK, D. (eds.). Matrices of Genre: Authors, Canons, and Society. Cambridge, Mass.: Harvard University Press, 2000, p. 205-219.

GALE, M. R. Lucretius and previous poetic traditions. In: GILLESPIE, Stuart; HARDIE, Philip (ed.). The Cambridge Companion to Lucretius. Cambridge University Press, 2007, p. 59-75.

GRIMAL, P. A Civilização Romana. Portugal: Edições 70, 2017.

GRIMAL, P. A Mitologia Grega. São Paulo: Brasiliense, 1984.

GRIMAL, P. O Século de Augusto. Portugal: Edições 70, 1992.

GUMBRECHT, H. U. [Resenha] Wolfgang Iser: Der Akt des Lesesn. Theorie ästhetischer Wirkung. Amsterdam: Verlag B. R. Grüner, Poetica., n. 9. S. 522-534, 1977.

HORACE. Satires. Epistles. The Art of Poetry. Trad. H. Rushton Fairclough. Harvard: Harvard University Press, 1926. (Loeb Classical Library).

ISER, W. O Jogo do Texto. In: LIMA, L. C. A literatura e o leitor: textos de estética da recepção. Rio de Janeiro: Paz e Terra, 1979, p. 105-118.

JAEGER, W. Paideia: a formação do homem grego. São Paulo: Martins Fontes, 2003.

JAUSS, H. R. A história da literatura como provocação a teoria literária. São Paulo: Ática, 1994.

LE GOFF, J. São Luís. Biografia. São Paulo: Record. 2002.

LIMA, L. C. A Literatura e o Leitor: textos de estética da recepção. Rio de Janeiro: Paz e Terra, 1979.

LONGINUS. On the Sublime. Trad. Stephen Halliwell. Harvard: Harvard University Press, 1995. (Loeb Classical Library).

LUCRETIUS. De rerum natura. Trad. W. H. D. Rouse. Rev. Martin Fergunson Smith. Londres: Harvard University Press, 1992.

LUCRETIUS. De rerum natura. Trad. Agostinho da Silva; Amador Cisneiros; Jaime Bruna. São Paulo: Abril Cultural, 1985.

MARCUS MANILIUS. Astrologia. Trad. Francisco Calero; Maria José Echarte. Madrid: Gredos, 1996. 
MARCUS MANILIUS. Astronômicas: tradução, introdução e notas. Trad. Marcelo Vieira Fernandes. São Paulo: Ed. da USP, 2006.

MARCUS MANILIUS. Astronomicas. Trad. G. P. Goold. Cambridge: Harvard University Press; London: Heinemann, 1977. (Loeb Classical Library).

MARKOVIĆ, D. The Rhetoric of Explanation in Lucretius' De rerum natura. Leiden: Brill, 2008.

MARROU, H.-I. História da Educação na Antiguidade. Campinas: Kírion, 2017.

MITSIS, P. Committing Philosophy on the Reader: Didactic Coercion and Reader Autonomy in De Rerum Natura. Materiali e discussioni per l'analisi dei testi classici, n. 31, p. 111-128, 1993.

NAUMANN, M. Recepscão literária, considerada teoricamente. Berlim: Akademic-Verlag, 1973.

NEUBURG, Matt. Hitch your wagon to a star: Manilius and his two addressees. Materiali e discussioni per l'analisi dei testi classici, n. 31, p. 243-283, 1993.

OVID. Fasti. Trad. James G. Frazer. Harvard: Harvard University Press, The Loeb Classical Library, 1931.

PÖHLMANN, E. Charakteristika des römischen Lehrgedichts. Berlim: De Gruyter, 1973.

QUINTILIAN. The Orator's Education. Trad.: Donald A. Russell. London: Harvard University Press, 2002. (The Loeb Classical Library).

SILVA, G. V. da. Política, ideologia e arte poética em Roma: Horácio e a criação do Principado. Politeia: História e Sociedade, Vitória da Conquista, v.1., n.1, p. 29-51, 2001.

TOOHEY, P. Epic Lessons: An introduction to ancient didactic poetry. Londres; Nova York: Routledge, 2010.

TREVIZAM, M. Poesia didática: Virgílio, Ovídio e Lucrécio. Campinas: Ed. da Unicamp, 2014.

VIRGIL. Eclogues. Georgics. Aeneid: Books 1-6. Trad.:H. Rushton Fairclough. Harvard: Harvard University Press, The Loeb Classical Library, 1999.

VOLK, K. Manilius and his Intellectual Background. New York: Oxford University Press, 2009.

VOLK, K. The Poetics of Latin Didactic: Lucretius, Vergil, Ovid, Manilius. Oxford: Oxford University Press, 2002. 